\title{
Design of a perfluorocarbon tracer based monitoring network to support monitoring verification and accounting of sequestered $\mathrm{CO}_{2}$
}

\author{
T. Watson and T. Sullivan \\ Brookhaven Science Associates, PO Box 5000, Upton, NY 11973-5000, USA
}

\begin{abstract}
The levels of $\mathrm{CO}_{2}$ in the atmosphere have been growing since the beginning of the industrial revolution. The current level is $391 \mathrm{ppm}$. If there are no efforts to mitigate $\mathrm{CO}_{2}$ emissions, the levels will rise to $750 \mathrm{ppm}$ by 2100 . Geologic carbon sequestration is one strategy that may be used to begin to reduce emissions. Sequestration will not be effective unless reservoir leak rates are significantly less than $1 \%$. There must be rigorous monitoring protocols in place to ensure sequestration projects meet regulatory and environmental goals. Monitoring for $\mathrm{CO}_{2}$ leakage directly is difficult because of the large background levels and variability of $\mathrm{CO}_{2}$ in the atmosphere. Using tracers to tag the sequestered $\mathrm{CO}_{2}$ can mitigate some of the difficulties of direct measurement but a tracer monitoring network and the levels of tagging need to be carefully designed. Simple diffusion and dispersion models are used to predict the surface and atmospheric concentrations that would be seen by a network monitoring a sequestration site. Levels of tracer necessary to detect leaks from 0.01 to $1 \%$ are presented and suggestions for effective monitoring and protection of global tracer utility are presented.
\end{abstract}

\section{INTRODUCTION}

There has been a growth in demand for energy since the beginning of the industrial revolution. The atmospheric concentration of $\mathrm{CO}_{2}$ is increasing with this growth. The preindustrial atmospheric background level was $280 \mathrm{ppm}$; by 1958 this had risen to $315 \mathrm{ppm}$; and in 2005 it had risen to $379 \mathrm{ppm}$ (1). The current atmospheric level is $391 \mathrm{ppm}$ (2). The rate of emissions growth is also increasing. The quantity of $\mathrm{CO}_{2}$ emissions grew by $1 \%$ per year in the period from 1980-2000. This rate had increased to greater than 3\% per year in the period 2000-2005 (3). If there are no changes in these trends, the business as usual projection, the IPCC predicts that $\mathrm{CO}_{2}$ emissions will increase to $77 \mathrm{Gt}$ per year by the year 2100 , there will be $9,000 \mathrm{Gt}$ emissions of $\mathrm{CO}_{2}$ into the atmosphere over the $21^{\text {st }}$ century and the concentration will rise to $750 \mathrm{ppm}$ by 2100 (1), (4), (3).

Stabilization of atmospheric levels of GHGs will require a mix of strategies (5), (6) including increasing energy efficiency, switching to energy sources that do not produce $\mathrm{CO}_{2}$ such as nuclear and solar energy and wind power, and reducing the $\mathrm{CO}_{2}$ emissions from fossil fuel energy production through carbon capture and storage (CCS). CCS will act as a bridging technology to facilitate a transition from fossil fuels to a sustainable energy based economy. Sequestration technology has been successfully used in commercial applications and numerous demonstration projects are in place to provide the research necessary for development and application of this technology. The focus of sequestration programs is large point sources of $\mathrm{CO}_{2}$; there are $8,100 \mathrm{CO}_{2}$ point sources globally where CCS could be employed (4). Coal fired power plants are the largest, most common of these sources. They produce $40 \%$ of anthropogenic $\mathrm{CO}_{2}$ emissions and supply approximately $50 \%$ of US energy generation. A $1000 \mathrm{~mW}$ coal fired plant will produce approximately 8.6 million tons of $\mathrm{CO}_{2}$ per year over a 30 -year lifetime (7). A minimum of $90 \%$ reduction of
$\mathrm{CO}_{2}$ emissions from coal fueled power plants is required to stabilize atmospheric $\mathrm{CO}_{2}$ levels. The goal of the US Department of Energy (DoE) sequestration program is to have advanced CCS technology ready for large scale demonstration in 2020 (8).

Monitoring Verification and Accounting (MV\&A) at sequestration sites is necessary to insure regulatory compliance, health and safety of local populations and ecosystems, and ensure the global environmental benefit of sequestration projects. CCS will not gain acceptance as a climate mitigation strategy without robust MV\&A protocols in place.

\section{GEOLOGIC $\mathrm{CO}_{2}$ SEQUESTRATION}

Geologic Sequestration of $\mathrm{CO}_{2}$ is the removal of $\mathrm{CO}_{2}$ from combustion effluent and placing it in permanent storage deep underground. It consists of three parts:

- Capture of $\mathrm{CO}_{2}$ from major stationary sources;

- Transporting it to a storage site, probably by pipeline; and

- Permanent storage of $\mathrm{CO}_{2}$ underground.

Total geologic storage capacity for $\mathrm{CO}_{2}$ is estimated at 1,100 to $3,400 \mathrm{Gt}$ (4), (9).

Three types of geological formations are under consideration for storage.

The first type is mature and oil and gas fields. These natural reservoirs have stored hydrocarbons safely for millions of years. Supercritical $\mathrm{CO}_{2}$ injection is used routinely by the oil and gas industry for enhanced oil recovery (EOR). Injection of the $\mathrm{CO}_{2}$ decreases the oil viscosity and increases oil production while leaving $\mathrm{CO}_{2}$ in the depleted oil reservoir (10). The extraction of otherwise inaccessible oil also increases the space available for $\mathrm{CO}_{2}$ storage. EOR using $\mathrm{CO}_{2}$ was begun in 1970s (7). Approximately $30 \mathrm{Mt}$ of $\mathrm{CO}_{2}$ per year is injected for EOR in the US (11).

This is an Open Access article distributed under the terms of the Creative Commons Attribution License 2.0, which permits unrestricted use, distribution, and reproduction in any medium, provided the original work is properly cited. 
The second type of geological formation is unmineable coal beds. It is expected that injection of $\mathrm{CO}_{2}$ in these formations will also produce natural gas (12), (7).

The third type of geological formation under consideration is deep saline aquifers. These are formations 100 s of meters to kilometers underground that are saturated with water which is not suitable for household or agricultural use because it contains high levels of dissolved salts. These formations are accessible globally over large areas - approximately $2 / 3$ of land area in the US is located above deep saline formations. They have the most potential capacity for carbon storage of the three geological features under consideration and, because they are so geographically extensive, will allow storage of captured $\mathrm{CO}_{2}$ near production sources (7), (12), (13).

\section{RESERVOIR INTEGRITY}

\subsection{Leakage pathways}

Leakage during transport or directly from the reservoir can reduce or eliminate the effectiveness of CCS. Reservoir Leakage pathways include pore systems in cap rock; openings in cap rock caused by natural fractures and faults; and, the most likely pathways, man-made faults in improperly sealed new or abandoned wells (14). The threat of abandoned wells is significant in places where CCS may be applied in conjunction with EOR. There are 350,000 existing wells in the Alberta Basin and 20,000 wells new drilled per year (7), (1). There have been 1.5 million oil and gas wells drilled in Texas (15). The location and condition of many of these wells may not be documented.

There are other effects that may compromise the integrity and reduce the maximum storage capacity of geologic reservoirs. The injection process may cause a rise in reservoir pressure that forces $\mathrm{CO}_{2}$ to enter the cap rock pores or exceeds the pressure that will fracture the containing formation. Other undesirable effects may be the displacement and transport of the existing formation fluid to the oceans, to the atmosphere, or to subsurface formations such as mines, or basements. There also may be displacement of brine or other contaminants into aquifers (16)

\subsection{Acceptable leak rates}

The leak rate from geological storage reservoirs must be less than $1 \%$. Hepple and Benson (6) determined that a $1 \%$ leak rate will result in the return on most of the sequestered carbon to the atmosphere after 400 years. They show that long term global performance requirement for stabilization of atmospheric levels at 350,450 , or $550 \mathrm{ppm}$ required a leak rate less than $0.01 \%$; that stabilization at 650 to $750 \mathrm{ppm}$ required a leak rate less than $0.1 \%$; and that rates of 0.01 to $0.1 \%$ are required to achieve mitigation of climate effects of atmospheric $\mathrm{CO}_{2}$ (16). A $0.01 \%$ leak rate results in $90 \%$ retention for 1000 years while $0.001 \%$ results in $99 \%$ retention for 1000 years. They also assert that these rates are technologically achievable. The DOE performance target for demonstration projects is a leak rate less than $1 \%$ of stored amount (17).

\section{MONITORING VERIFICATION AND ACCOUNTING}

\subsection{Goals of monitoring}

Monitoring, Verification and Accounting (MV\&A) is used to describe measurement and observations designed to support the research, health and safety, regulatory, and environmental goals of CCS programs.

The research goals identified by the US DoE MV\&A program are:

- To understanding storage processes,

- To map $\mathrm{CO}_{2}$ subsurface movement, and

- To evaluate $\mathrm{CO}_{2}$ interactions with the target geological formation.

These goals are designed to further the understanding of sequestration processes and provide data for model development and validation.

The Health and Safety goals of the DoE MV\&A program are designed to ensure that the local environment and human health are protected. Large $\mathrm{CO}_{2}$ leaks can lead to health and safety issues. In 1986 a massive natural release of $\mathrm{CO}_{2}$ from a lake bottom in Cameroon killed more than 1,700 people (18). Basements and confined spaces might be at risk from reservoir leaks along fault lines. Local groundwater may be at risk from displaced brine or contaminants released into aquifers by the chemical action of the sequestered $\mathrm{CO}_{2}$.

The Global environmental goals of the DoE MV\&A program are designed to ensure the achievement of long term greenhouse gas reduction targets (17), (19) and the regulatory requirements necessary to account for $\mathrm{CO}_{2}$ stored for cap and trade, and treaty obligations.

MV\&A programs will also provide a technical basis to assist in resolving legal disputes such as the alleged leaks from the disputes Weyburn EOR project (20).

\subsection{Levels of monitoring}

\subsubsection{Sub surface}

The geological formations where sequestration is proposed are hundreds of meters to kilometers underground. Mapping of the $\mathrm{CO}_{2}$ pool in these reservoirs can be accomplished using 3-D seismic imaging (21), electrical resistivity tomography (22), gravitrometry, and direct measurement of samples collected from monitoring wells (23).

\subsubsection{Near surface}

Near surface monitoring consists of soil gas analysis and testing ground water. Analysis of ground water can detect changes in the composition that may indicate leaks of $\mathrm{CO}_{2}$ or brine into the local aquifers and can be used to identify natural or introduced tracer compounds. Inelastic neutron scattering can also be used to detect excess carbon in the soil (24). All these methods rely on pre-injection surveys to establish a baseline levels against which post-injection anomalies can be evaluated for indications of leaks. 


\subsubsection{Atmosphere}

Detection of reservoir leaks by direct measurement of $\mathrm{CO}_{2}$ at the surface will be difficult because of the high background levels and large variability of $\mathrm{CO}_{2}$ in the atmosphere. This variability is a result of natural and anthropogenic sources as well as diurnal and seasonal effects. Eddy correlation methods have been proposed as a means to directly detect $\mathrm{CO}_{2}$ leaks at the surface. This technique consists of fast response concentration measurements made in conjunction with $3-\mathrm{D}$ wind data to determine surface $\mathrm{CO}_{2}$ fluxes. This method is most effective when used in flat terrain with homogeneous vegetation. Other methods, including remote sensing using FTIR spectroscopy and satellite imagery have been proposed (17). Chemical compounds known as tracers can be used to tag the injected $\mathrm{CO}_{2}$. When these compounds are detected they indicate the presence of tagged $\mathrm{CO}_{2}$ and if the tagging ratio is known can be used to determine the size of the reservoir leak. Tracer compounds include natural isotopes that are unique to the sequestered $\mathrm{CO}_{2}$ and introduced compounds such as noble gases, $\mathrm{SF}_{6}$, and perfluorocarbon compounds (12), (24). Transport and dispersion along pathways both above and below the surface will significantly dilute the plume, so the quantity of tracer used to tag the $\mathrm{CO}_{2}$ must be sufficient to allow detection at the levels necessary to ensure sequestration is effective.

\section{DISPERSION MODELS}

\subsection{Subsurface}

A model of subsurface transport is needed to determine the concentration of the tracer at the surface that will result from a leak in the cap rock. We developed a simple diffusion model with the assumptions that the rock above the reservoir cap acts as a porous medium and that fracture flow does not occur after the $\mathrm{CO}_{2}$ escapes from the reservoir. If there was a subsurface fracture there would be a direct route to the surface and transport may be much faster.

The basic transport equation for diffusion controlled movement is:

$$
\partial C / d t=D \nabla^{2} C+\frac{Q}{\theta} .
$$

Where C is concentration, D is the diffusion coefficient; $\mathrm{Q}$ is the release rate of the material being transported, and $\theta$ is the soil porosity.

\subsubsection{Model results}

The models were run with a diffusion coefficient $\mathrm{D}=$ $110^{-2} \mathrm{~cm}^{2} / \mathrm{s}$ and a source at depths from $100 \mathrm{~m}$ to $1 \mathrm{~km}$. The calculated times for a leak to reach the surface with a dilution factor of $10^{-6}$ are given in Table 1 .

Examining the results in Table 1, it is clear that unless there is a method to transport the tracer to within
Table 1. Time required for normalized concentrations near the surface to reach $10^{-6}$.

\begin{tabular}{lc}
\hline Source Depth $(\mathrm{m})$ & $\begin{array}{c}\mathrm{D}=10^{-2} \mathrm{~cm}^{2} / \mathrm{s} \\
\text { Time (years) }\end{array}$ \\
\hline 100 & 12 \\
200 & 60 \\
300 & 130 \\
400 & 240 \\
500 & 380 \\
600 & 570 \\
700 & 800 \\
800 & 1150 \\
900 & 1400 \\
1000 & 1750 \\
\hline
\end{tabular}

Table 2. Pasquill Gifford stability classes.

\begin{tabular}{lc}
\hline Stability class & Definition \\
\hline A & very unstable \\
B & unstable \\
C & slightly unstable \\
D & neutral \\
E & slightly stable \\
F & stable \\
\hline
\end{tabular}

100 meters of the surface, the time required to be able to detect the leak at the surface will be tens to hundreds of years. Diffusion controlled point source leakage from faults in the cap rock is not a mechanism that will cause a significant loss of sequestered $\mathrm{CO}_{2}$.

The diffusion coefficient used in the calculations is typical for sandy soils. Soils with high clay content may exhibit even lower diffusion coefficients and longer transport times. The model only considers the case of open porosity between the release depth and the surface. If there is an aquifer between the release and the surface, transport will be significantly different from the model results and it will be difficult to predict the transport effects. Monitoring must include ground water measurements.

\subsection{Atmospheric dispersion model}

A simple Gaussian Plume model was used to predict atmospheric dispersion (25). The concentration at any point downwind, $\mathrm{x}$, and a distance $\mathrm{y}$ from the center line of the plume, is then given by:

$$
\chi(x, y, z=0,0)=\frac{Q}{\pi u \sigma_{y} \sigma_{z}} \exp \left[-\frac{y^{2}}{2 \sigma_{y}^{2}}\right] .
$$

The source and receptors were both at ground level, $\mathrm{z}=0$. The standard deviations in the $\mathrm{z}$ and $\mathrm{y}$ directions are determined by the horizontal and vertical fluctuations in the wind. The standard deviations have been parameterized according to a system of identifying the wind fluctuations, known as the Pasquill-Gifford stability classes (Table 2). The dilution isopleths for stability class D, neutral, are presented in Figure 1. 


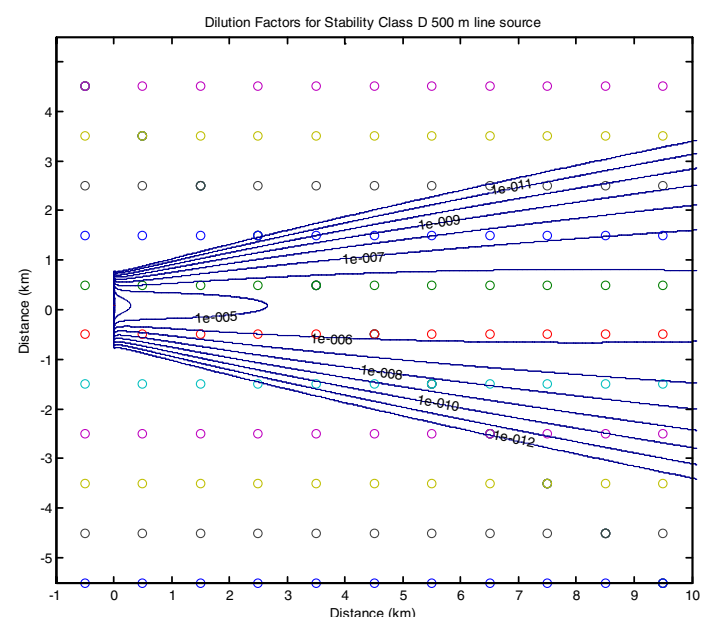

Figure 1. Isopleths of dilution factors for a $1 \mathrm{~km}$ line source and stability class D on a $10 \times 10 \mathrm{~km}$ grid. Open circles represent the sampling sites.

Table 3. $\left[\mathrm{CO}_{2}\right]$ at $1 \mathrm{~km}$ distance from source for a dilution factor of $10^{-5}$.

\begin{tabular}{|c|c|c|}
\hline $\mathrm{Q}$ & \multicolumn{2}{|c|}{$\chi\left(\mathrm{CO}_{2}\right)$} \\
\hline leak rate & \multicolumn{2}{|c|}{ concentration } \\
\hline$\left(\%\right.$ year $\left.^{-1}\right)$ & mixing ratio & (ppmv) \\
\hline $1.00 \%$ & $4.2 \mathrm{E}-04$ & 416 \\
\hline $0.10 \%$ & 4.2E-05 & 42 \\
\hline $0.05 \%$ & $2.1 \mathrm{E}-05$ & 21 \\
\hline $0.01 \%$ & 4.2E-06 & 4 \\
\hline
\end{tabular}

Table 4. PFTs commonly used as tracers.

\begin{tabular}{lll}
\hline Acronym & Chemical Name & Formula \\
\hline PDCB & Perfluorodimethylcyclobutane & $\mathrm{C}_{6} \mathrm{~F}_{12}$ \\
PMCP & Perfluoromethylcyclopentane & $\mathrm{C}_{6} \mathrm{~F}_{12}$ \\
PMCH & Perfluoromethylcyclohexane & $\mathrm{C}_{7} \mathrm{~F}_{14}$ \\
o-PDCH & Perfluoro-1,2-dimethylcyclohexane & $\mathrm{C}_{8} \mathrm{~F}_{16}$ \\
i-PPCH & Perfluoroisopropylcyclohexane & $\mathrm{C}_{9} \mathrm{~F}_{18}$ \\
PTCH & Perfluorotrimethylcyclohexane & $\mathrm{C}_{9} \mathrm{~F}_{18}$ \\
\hline
\end{tabular}

The model illustrates the difficulty of directly measuring $\mathrm{CO}_{2}$ at leak rates less than $1 \%$. Atmospheric $\mathrm{CO}_{2}$ levels undergo large diurnal, seasonal, and site specific fluctuations. One monitoring station has recorded $100 \mathrm{ppm}$ changes over a single day (26). The results of the model for concentrations of $\mathrm{CO}_{2}$ at a receptor $1 \mathrm{~km}$ from the source of the leak are given in Table 3. It is obvious that detection of a leak of less than $0.1 \%$ will be difficult to distinguish from typical variations caused be meteorology, natural cycles, and local combustion sources.

The tagging of the injected $\mathrm{CO}_{2}$ with a tracer is a technique that can be used to overcome the difficulties of direct measurement. The detection limit for perfluorocarbon tracers is on the order of $100 \mathrm{fg}\left(10^{-15} \mathrm{~g}\right)$ (24) and the background levels are in the parts per quadrillion level, 9 orders of magnitude less than $\mathrm{CO}_{2}$. The perfluorocarbon compounds commonly used as tracers are given in Table 4 and backgrounds and atmospheric loads for 5 PFTs are given in Table 5.
Table 5. Background atmospheric concentration and total atmospheric load of PFTs (24)

\begin{tabular}{cccccc}
\hline & PDCB & PMCP & PMCH & oPDCH & ptPDCH \\
\hline $\begin{array}{c}\text { Bkgrd (ppqv) } \\
\text { Total }\end{array}$ & 3 & 8 & 8 & 1 & 7 \\
$\begin{array}{c}\text { Atmospheric } \\
\text { load (metric } \\
\text { tons) }\end{array}$ & 140 & 430 & 500 & 71 & 500 \\
\hline
\end{tabular}

Table 6. PFT tagging levels for detection at $1 \mathrm{~km}$ distance from the source and a dilution factor of $10^{-5}$.

\begin{tabular}{l|c|c|c}
\hline $\begin{array}{l}\mathrm{CO}_{2} \\
\text { leak rate } \\
\left(\text { year }^{-1}\right)\end{array}$ & $\begin{array}{c}\text { Q PFT/QCO2 } \\
\text { ppmm }\end{array}$ & $\begin{array}{c}\text { kg PFT } \\
\text { year }^{-1}\end{array}$ & $\begin{array}{c}\text { tons PFT } \\
\text { total }\end{array}$ \\
\hline $1.00 \%$ & $1.2 \mathrm{E}-04$ & 1 & $3.2 \mathrm{E}-02$ \\
$0.10 \%$ & $1.2 \mathrm{E}-03$ & 10 & $3.2 \mathrm{E}-01$ \\
$0.05 \%$ & $2.4 \mathrm{E}-03$ & 20 & $6.3 \mathrm{E}-01$ \\
$0.01 \%$ & $1.2 \mathrm{E}-02$ & 110 & $3.2 \mathrm{E}+00$ \\
\hline
\end{tabular}

The extremely low detection limits and background levels make PFTs very useful in detecting leaks in the atmosphere.

A concept for a sampling network was designed using the following criteria and assumptions:

- Significant leaks will only occur from direct transport to the surface through faults or active or abandoned wells.

- The $\mathrm{CO}_{2}$ source will be a $1000 \mathrm{MW}$ coal fired power plant which will release.

- 8.6 million tons of $\mathrm{CO}_{2}$ per year,

- Over a 30 year lifetime.

- $100 \mathrm{~km}^{2}$ surface area above the storage pool will be monitored.

- The sampling grid will consist of:

- Passive sampling,

- 100 sampling locations,

- $1 \mathrm{~km}$ spacing.

- Sample analysis will be monthly.

- Only a subset of samples will be analyzed.

- PFT background of 10 ppqv.

- Signal to background ratio of $\sim 1$.

- Acceptable leak rate $<1 \%$ per year.

The locations of the passive sampling sites are shown relative to the leak plume as open circles in Figure 1. Table 6 shows the PFT levels necessary to tag sequestered $\mathrm{CO}_{2}$ to detect leak levels from 0.01 to $1 \%$ of the total sequestered over the lifetime of a $1000 \mathrm{~mW}$ coal fired plant.

\section{CONCLUSIONS}

Perfluorocarbon tracers offer advantages over direct measurement of $\mathrm{CO}_{2}$ for monitoring verification and accounting at CCS sites. The design of the monitoring network and the sampling strategy has to be carefully planned to take advantage of the unique properties of PFTs while accomplishing the goals of monitoring. A grid of 
passive samplers with a $1 \mathrm{~km}$ spacing is the minimum necessary to be able to detect leaks at reasonable tagging levels. Monthly sample collection is necessary to be able to distinguish between background levels and a leak. A strategy for selectively analyzing samples from the grid should be developed based on the site meteorology. This can be used to select the samples most likely to be in the plume of a leak and reduce analytical costs.

A global agreement on the use of tracers for monitoring CCS projects should be developed. The utility of PFTs or any other tracer will be lost if the background levels are allowed to rise indiscriminately. Global background monitoring of tracer levels should be part of a comprehensive strategy of CCS MV and A.

\section{References}

[1] Solomon, S., et al. 2007: Technical Summary. [ed.] S., D. Qin, M. Manning, Z. Chen, M. Marquis, K.B. Averyt, M. Tignor and H.L. Miller Solomon. In: Climate Change 2007: The Physical Science Basis. Contribution of Working Group I to the Fourth Assessment Report of the Intergovernmental Panel on Climate Change. Cambridge, United Kingdom and New York, NY, USA. : Cambridge University Press. http://www.ipcc.ch/publications_and_data/ publications_ipcc_fourth_assessment_report_wg1_ report_the_physical_science_basis.htm

[2] Trends in Atmospheric Carbon Dioxide. NOAA Earth System Research Laboratory global Monitoring Division. [Online] [Cited: June 6, 2011.] http://www . esrl. noaa.gov/gmd/ccgg/trends/global. html

[3] Solomon, S., et al. Proceedings of the National Academy of Science 106, 1704-1709 (2009)

[4] Dooley, J.J., Dahowski, R.T. and Davidson, C.L. Carbon Dioxide Capture and Geologic Storage. s.l.: Batelle Memorial Institute (2006)

[5] Pacala, S.W. and R.H., Socolow, Science 305 (2004)

[6] Hepple, R.P. and Benson, S.M., Environ Geol. 47, 576-585 (2005)

[7] Benson, S. and Cook, P. Chapter 5: Underground Geological Sequestration. [book auth.] Prepared by Working Group III of the Intergovernmental Panel on Climate Change. [ed.] B.O. Davidson, H.C. de Coninck, M. Loos, and L.A. Meyer [Metz. IPCC, 2005: IPCC Special Report on Carbon Dioxide Capture and Storage. Cambridge University Press. http://www.ipcc.ch/pdf/specialreports/srccs/srccs_chapter5.pdf

[8] National Energy Technology Laboratory. DOE/NETL Carbon Dioxide Capture and Storage $R D \& D$
Roadmap. U.S. Department of Energy/ Office of Fossil Energy/National Energy Technology Laboratory (2010)

[9] Figueroa, J.D., et al. Inernational Journal of Greenhouse Gas Control 2, 9-20 (2008)

[10] Holtz, M.H., Nance, P.K. and Finley, R.J. Environmental Geosciences 8, 187-199 (2001)

[11] Wilson, E.J., Johnson, T.L. and Keith, D.W. Environmental Science and Technology 37, 34763483 (2003)

[12] White, C.M., et al. J. Air \& Waste Manage. Assoc. 53, 645-715 (2003)

[13] Plasynski, S. I., et al. Critical Reviews in Plant Science 28, 123-138 (2009)

[14] Gasada, S. E., Bachu, S. and Celia, M.A. Environmental Geology 46, 707-720 (2004)

[15] Ha-Duong, M. and Keith, D.W. Clean Technology Environmental Policy 5, 181-191 (2003)

[16] Chadwick, A., et al. BEST PRACTICE FOR THE STORAGE OF CO2 IN SALINE AQUIFERS. Keyworth, Nottingham, British Geological Survey,. British Geological Survey Occasional Publication No. 14. ISBN: 978-0-85272-610-5 (2008)

[17] National Energy Technology Laboratory. Monitoring, Verification, and Accounting of CO2 Stored in Deep Geologic Formations.: National Energy Technology Laboratory, DOE/NETL-311/081508 (2009)

[18] Clarke, T. Nature 409, 554-555 (2001)

[19] On Leakaage from Geologic Storage Reservoirs of CO2. Pruess, K. Berkeley California: Lawrence Berkeley National Laboratory, 2006. Proceedings CO2SC Symposium (2006)

[20] Orcutt, M. Scientific American https://www. scientificamerican.com/article.cfm? id = weyburncarbon-storage-alleged-leak (2011)

[21] Torp, T. and Gale, J. Energy 29, 1361-1369 (2004)

[22] Wurdemann, H., et al. Inernational Journal of Greenhouse Gas Control 4, 938-951 (2010)

[23] Zimmer, M., et al. International Journal of Greenhouse Gas Control. doi:10.1016.j.iiggc2010.11.007 (2010)

[24] L. Wielopolski, A. Chatterjee, S. Mitra, R. Lal. Geoderma 160, 394-399 (2011)

[25] Watson, T.B., et al. Environmental Science and Technology 41, 20 (2007)

[26] Turner, D.B. Workbook of Atmospheric Dispersion Estimates: An Introduction of Dispersion Modeling. Boca Raton: CRC Press (1994)

[27] Massen, F., Kies, A. and Harpes, N. Seasonal and Diurnal CO2 Patterns at Diekirch, LU. [Online]. http://meteo.lcd.lu/papers/co2_patterns/co2_patterns. html. (2007) 